\title{
Minicomputer-administered tasks in the study of effects of sustained work on human performance
}

\author{
DAVID H. RYMAN, PAUL NAITOH, and CARL E. ENGLUND \\ Environmental Physiology Department, Naval Health Research Center, San Diego, California
}

\begin{abstract}
Six tasks administered on a MINC-11 minicomputer were used in studying the effects of long, continuous work periods and fatigue on physical and cognitive task performance. Submaximal physiological workload measurement was done during one of these tasks for a subject walking on a treadmill. The MINC-11 system is described, as are the six tasks programs. Four of these tasks measured various types of reaction times, another involved complex information processing, and one appraised moods, physical symptoms, fatigue, and the physiological status of subjects.
\end{abstract}

Laboratory measurements of changes in human performance during continuous (sustained) work had been carried out before the widespread availability of digital computers (EcoSystems, 1977; Hartman, Benel, \& Storm, 1980;Kennedy, Bittner, Carter, Krause, Harbeson, McCafferty, Pepper, \& Wiker, 1980; McKenzie, White, \& Hartman, 1969; Moran \& Mefferd, 1959; Morgan, Brown, \& Alluisi, 1974; Naitoh, 1981; Opstad, Ekanger, Nummestad, \& Raabe, 1978; Reilly \& Cameron, 1968). Computer-administered testing has facilitated the repeated presentation of many different tasks and the collection of data in the study of the effects of sustained work (Angus, Innes, Heselgrave, \& Pearce, 1980; Foree, Eckerman, \& Elliot, 1984; Englund, Naitoh, Ryman, \& Hodgdon, 1983; Heselgrave \& Angus, 1983; Mullaney, Kripke, Fleck, \& Johnson, 1983; Olson, Moeller, \& Laxar, 1973; Naitoh, Englund, \& Ryman, 1982; Thorne, Genser, Sing, \& Hegge, 1983). Computers, of course, enable rapid analysis of the collected data.

The purpose of this paper is to describe the series of computer-presented tasks that have been used in studies of the effects of exercise and sleep loss resulting from sustained work on human performance. These programs have been used in studies involving 48 pairs of U.S. Marine Corps subjects.

This work represents Report No. 83-21, supported by the Naval Medical Research and Development Command, Department of the Navy, under Work Unit MF58.528.01B-0003. The views presented in this paper are those of the authors. No endorsement by the Department of the Navy has been given or should be inferred. The task programs described here were programmed by Raymond Hilbert, and technical assistance was provided by Donald Irwin. The authors would like to thank Commander D. E. Wood for his critical reading of and editorial suggestions for this manuscript. The authors' mailing address is: Environmental Physiology Department, Naval Health Research Center, P.O. Box 85122, San Diego, CA 92138-9174.

\section{METHOD}

\section{Measures}

Tasks were selected on an a priori basis for sensitivity to the effects of sleep loss and fatigue (e.g., Wilkinson, 1964; Williams, Lubin, \& Goodnow, 1959). Three of these tasks correspond to Donder's (1868) model of reaction time measure types: simple reaction time (SRT; stimulus detection followed by response), disjunctive reaction time (DRT; stimulus detection followed by sensory discrimination and response), and choice reaction time (CRT; correct choice or response selection added to DRT) (Companion \& Corso, 1982; Grice, Nullmayor, \& Spiker, 1982). These three tasks all measured response times to visually presented stimuli. A fourth task primarily measured motor response speed and consistency (no stimulus detection), and the fifth task, representing complex information processing, was also incorporated into the computer-administered test battery. Along with these tasks, the computer surveyed moods, physical symptoms, fatigue, and physiological status of volunteer subjects (i.e., oral temperature, blood pressure, and grip strength).

During the week-long study, subjects were administered up to 501 -h-long sessions of different combinations of six computer-given tasks, along with several other tasks not presented on the computer. The tight scheduling of all of these tasks required speed in both the operating system and program execution, for the minicomputer system used. Since four of these were reaction time tasks, and two required 5-V TTL signal processing, a minicomputer with both a programmable clock and an A/D converter interface was required. The primary measure in these studies-workload-includes the measurement and collection of heart rate, oxygen consumption, $\mathrm{CO}_{2}$ production, the volume, temperature, and humidity of inspired air, and the subject's treadmill speed and grade. Obviously, many A/D input 
channels were needed, and some signals required preamplification. With a sampling rate of 50 times a second for these measures, along with conversion of $A / D$ voltages into correct units, and manipulation through about 20 formulas, ease and speed of data acquisition and speed in program execution were of paramount importance.

\section{Designs}

The experimental designs for studies of long, continuous "sustained operations" (SUSOP) have called for hourly to every 3-or 4-h repeated use of all or some portion of these computer-administered task batteries. The results of studies applying these tasks have been published (Englund et al., 1983; Naitoh et al., 1982). The experimental designs of the studies have varied the physical workload levels of the experimental subjects as well as the length and type (nap-no nap) of rest between continuous work cycles. The work for the experimental subject is walking on a treadmill carrying a $22.7 \cdot \mathrm{kg}$ (50-lb) pack. The continuous work cycles involve the various combinations of tasks on the computer and other tests given 17 times on each of 2 days. What follows is a description of the computer system, the task programs, and data and scores generated in these studies. Table 1 summarizes types of tasks, task names, and performance measures used in the SUSOP studies.

\section{System}

The six tasks have been presented on both the Digital Equipment Corporation (DEC) MINC-11/03 and MINC$11 / 23$ models. MINC is an acronym for modular instrumentation computer. The MINC $11 / 03$ is a PDP. $11 / 03$ with $64 \mathrm{~K}$ ROM. The MINC $11 / 03$ can be upgraded to a MINC $11 / 23$, which is a PDP-11/23 with $128 \mathrm{~K}$ ROM and a floating-point chip. MINCs have an LSI $11 / 2$ CPU and a Q-bus. On the Q-bus lines, the data and address signals are multiplexed (shared, not dedicated, lines). There are clock, A/D converter, preamp, and other modules that can be configured with the
MINC. These modules are specialized boards that are directly on the Q-bus. The clock module has two programmable clocks and two Schmitt triggers. This MINC clock module is not the same as the PDP-11 lab system clock, since it has different addresses and status register bit indicators and the peripheral addresses are not the same. Therefore, the task programs described are not directly convertible to the PDP.11s without some program modifications and recompilation. The A/D module will support 16 single-ended input line channels, or 4 quasi-differential and 8 single-ended channels. The A/D is directly connected to the primary clock on the clock module. The settings on the clock module and some of the channel connectors on the $A / D$ are on the front panel of the MINC chassis, as opposed to internal connections and dip switch settings found on many specialized minicomputer boards. The MINC system used in presenting the six tasks has the A/D converter (MNCAD) and programmable clock (MNCKW) modules, two doubledensity floppy-disk drives (RXO2s), and an interactive terminal (VT105). The system also has three other peripherals: a second terminal (VT100), a printer (LA120), and a slave CRT monitor. The RT-11 (realtime, single-job, Versions 3 and 4) operating system was used because of its considerable speed advantages over the MINC basic hardware operating system in terms of booting the system, calling of programs, output to disk, etc. The raw data listing and scoring programs were written in FORTRAN IV (Versions 2.4 and 2.5). The task programming for the MINC was done in assembly language for reasons of speed in both program execution and operating system, timing, and the programmer's experience with MACRO-11 code. MINC module programming can also be done in BASIC and FORTRAN IV; however, the BASIC operating system and program execution speed was too slow to handle the schedule of tasks given in our experiments.

\section{Program Execution}

Two volunteer subjects from the U.S. Marine Corps were tested simultaneously. The experimental subject

Table 1

Task Types, Names, and Measures

\begin{tabular}{|c|c|c|}
\hline Type of Task & Task Name & Measures-Scores \\
\hline Motor Reaction Time & Tapping Task (TRAP) & $\begin{array}{l}\text { No. of responses each minute, } 10 \% \text { fastest, } 10 \% \text { slowest means and } \\
\text { SDs, no. of lapses }\end{array}$ \\
\hline Simple Reaction Time & Simple Reaction Time & $\begin{array}{l}60 \text { reaction times, } 10 \% \text { fastest, } 10 \% \text { slowest means and SDs, no. of } \\
\text { lapses }\end{array}$ \\
\hline Disjunctive Reaction Time & $\begin{array}{l}\text { Alpha-Numeric Visual } \\
\text { Vigilance Test }\end{array}$ & $\begin{array}{l}\text { Reaction time of correct responses, errors of commission, means and } \\
\text { SDs, no. of omissions }\end{array}$ \\
\hline Choice Reaction Time & Four Choice & $\begin{array}{l}\text { Reaction times, correct or incorrect; means and SDs for } 10 \% \text { fastest and } \\
10 \% \text { slowest, no. and } \% \text { correct responses }\end{array}$ \\
\hline Complex Information Processing & Logical Reasoning & $\begin{array}{l}\text { Questions given, responses, no. correct, no. incorrect, \% correct, no. of } \\
\text { questions answered }\end{array}$ \\
\hline Mood Symptoms, Fatigue & Mood-Physiology & $\begin{array}{l}\text { POMS scales, NHRC scales, blood pressure, oral temperature, grip } \\
\text { strengths, KOGI physical symptoms, SAM Subjective Fatigue Scale, SSS }\end{array}$ \\
\hline
\end{tabular}


was required to walk on a treadmill $.5 \mathrm{~h}$ of every $1 \mathrm{~h}$ of testing. The control subject remained seated in a chair in front of a monitor. Three data diskettes were needed to store data from a week-long study involving two volunteer subjects, each diskette having 17 session files of 19 to 26 blocks each.

Prior to data collection, diskettes were formatted and initialized, and the directory was set up by a command file using a short assembly language program to accept outputs from the computer.

The storage requirements for these task programs, listing-scoring programs, the operating system, and file creation programs are listed in Table 2 . The subjects are given verbal and written task descriptions and have up to four trials on each task on a training day. They then have a control-baseline day of 12 sessions, followed by the two 17-session continuous workdays. The trainingday trials are necessary to introduce the six tasks and the scheduling of them. Because, by the end of the control baseline day, much of the learning curve improvement should have occurred, most of the changes observed on the 2 continuous workdays should be due to fatigue and sleep loss.

\section{TASK DESCRIPTIONS}

\section{Task of Response Alternation Performance (TRAP)}

This tapping task, designed by Humphreys and used by Friedmann, Globus, Huntley, Mullaney, Naitoh, and Johnson (1977) and Naitoh et al. (1982) consists of a "box" with two $1-\mathrm{in}$. buttons connected to a flip-flop switch that outputs a 5.V TTL signal. This task primarily measures motor speed and consistency of reaction time over $6 \mathrm{~min}$. The output of each box was connected to a channel on the $A / D$ converter module on the computer. With their eyes closed, volunteer subjects pressed one of two buttons alternately at as steady a pace as they could with the first digit of their dominant hand. If alternate buttons were not pressed in $2.5 \mathrm{sec}$, a bell sounded to alert the subject. The interresponse intervals were recorded over a period of
$6 \mathrm{~min}$. At the end of $6 \mathrm{~min}$, a bell rang to indicate the end of the task. The number of button-presses each minute for each subject was recorded on the output floppy diskette along with the $10 \%$ fastest and $10 \%$ slowest response times over the 6-min period. Performance measures of extremely slow or fast responses were used because they had been shown to demonstrate the effects of sleep loss (Lisper \& Kjellberg, 1972; Williams et al., 1959).

The scoring program listed the number of buttonpresses per minute and the total number of presses over $6 \mathrm{~min}$ for each subject. Means and standard deviations for the $10 \%$ fastest and 10\% slowest interresponse intervals, along with the number of attentional "lapses," that is, $2.5 \mathrm{sec}$ with no response, were also printed out.

\section{Visual Simple Reaction Time Task}

The simple reaction time task, as initially developed by Lisper and Kjellberg (1972), who used an auditory signal, was modified for a visual signal. The visual signal task has been used in sleep loss research to measure reaction time to a stimulus (Herscovitch \& Broughton, 1981). It consists of 60 randomly spaced trials of clock ticks in 100ths of a second displayed on the terminal screen. Subjects are told to press any key on the keyboard the moment they see numbers (clock ticks) appear on the monitor. The clock ticks stop on the screen the moment any key is engaged or at 250 (i.e., $2.5 \mathrm{sec}$ after the start) when a bell rings. The response time remains on the screen for $0.5 \mathrm{sec}$, providing instant feedback to the subject. Intervals between the 60 clocktick presentations vary randomly from 1 to $11 \mathrm{sec}$, the mean interval being $6 \mathrm{sec}$.

The listing-scoring program lists all reaction times and computes the means and standard deviations for the 60 reaction times, the 6 fastest and 6 slowest, and the counts of the number of responses less than $2.5 \mathrm{sec}$ and the number of response lapses.

\section{Alpha-Numeric Visual Vigilance Task}

The Alpha-Numeric visual vigilance task (Hord,

Table 2

Floppy Diskette Storage Requirements for Compiled Programs and Data (Number of Blocks)

\begin{tabular}{|c|c|c|c|c|c|c|}
\hline & $\begin{array}{c}\text { Task } \\
\text { Program } \\
\end{array}$ & & $\begin{array}{l}\text { List/Score } \\
\text { Program }\end{array}$ & & $\begin{array}{l}\text { Stored Data } \\
\text { Each Session }\end{array}$ & \\
\hline Task Name & No. of Blocks* & $\mathrm{K}^{*}$ & No. of Blocks* & $\mathrm{K}^{*}$ & No. of Blocks* & $\mathrm{K}^{*}$ \\
\hline Alpha-Numeric Visual Vigilance Test & 41 & 10.3 & 43 & 10.3 & 3 & .8 \\
\hline Moods-Physiology & 17 & 4.3 & 28 & 7.0 & 2 & .5 \\
\hline Simple Reaction Time & 7 & 2.8 & 33 & 4.3 & 1 & .3 \\
\hline Tapping Task (TRAP) & 27 & 6.8 & 34 & 4.3 & 4 & 1.0 \\
\hline Logical Reasoning & 9 & 2.8 & 30 & 3.8 & 2 & .5 \\
\hline Four Choice & 14 & 3.5 & & & 8 & 2.0 \\
\hline File Setup & 4 & 1 & & & & \\
\hline Operating System & 67 & 16.8 & & & & \\
\hline
\end{tabular}

*256 bytes per block with either 436 blocks (single density) or 976 blocks (double density) on an 8-in. floppy diskette. 
1982; Naitoh, 1981) was developed at the Naval Health Research Center to measure long-term visual vigilance. This task consists of presentations, on the VT100 and a slave monitor, of random alphabetic characters or numbers at random intervals ranging between 6 and $14 \mathrm{sec}$, with a mean interval of $10 \mathrm{sec}$. The number or character is $10 \times 20 \mathrm{~mm}$ in size and remains on the screen for $10 \mathrm{msec}$. Subjects are instructed to press a hand-held, normally open pushbutton switch with their thumb every time an A or a 3 appears. The hand-held switches are connected to a TTL circuit that outputs a 5-V signal to an $\mathrm{A} / \mathrm{D}$ channel. Twenty $\mathrm{As}$ and $3 \mathrm{~s}$ are randomly mixed with 160 other characters and numbers given during this $30-\mathrm{min}$ task. The program measures response latencies. At the end of a 30-min task, all reaction times (in milliseconds) are stored on the output floppy diskette. Response times to non-As and non-3s are errors of commission and are stored as two's complement. Omissions-no responses to an $\mathrm{A}$ or a 3 in $5 \mathrm{sec}$-are stored as 5000 .

The Alpha-Numeric visual vigilance task was presented on the slave terminal by the computer; the task was administered to experimental subjects while they walked on a treadmill. Control subjects performed the task while seated in a chair. The computer is programmed to administer the visual vigilance task and to store and record spirometric readings (breath volume, oxygen consumption, and carbon dioxide production), $\mathrm{VO}_{2} \mathrm{ml} / \mathrm{kg}$, speed and grade of the treadmill, and heart rate. These physiological parameters were input directly to eight $\mathrm{A} / \mathrm{D}$ channels 50 times per second. The sampling rate of this physiological data required the use of a computer system like the MINC.

The listing-scoring program for the Alpha-Numeric task lists all responses during a $30-\mathrm{min}$ session, the number of correct responses (buttonpresses following an $\mathrm{A}$ or a 3), the number of errors of omission, and the number of errors of commission. The means and standard deviations for the correct responses, the five slowest correct responses, and the five fastest correct responses are also printed out, along with the percent-correct detection. An error of omission is declared when responses to an $A$ or a 3 are not made within $5 \mathrm{sec}$. In computing mean reaction time as well as the five slowest responses, errors of omission are added as reaction times of $5000(5 \mathrm{sec})$.

\section{Four-Choice Serial Reaction Time Task}

This task, developed by Wilkinson and Houghton (1975), can measure a subject's reaction time involving correctness of response. It consists of presentation of a blinking "+" (plus sign) imposed on the cursor in one of four quadrants of a video screen. The subjects are told to press the key (of four) on the terminal keyboard that corresponds to the quadrant with the blinking " + ." The blinking " + " remains in a quadrant until one of the four keys is pressed and then randomly reappears in one of the quadrants. If none of the four buttons is pressed within $2.5 \mathrm{sec}$, a bell rings at $0.1-\mathrm{sec}$ intervals until a response is made. This task lasts $6 \mathrm{~min}$, and the subjects are instructed to respond as accurately and as quickly as possible. Reaction times of all responses are recorded on floppy diskettes in 100ths of a second. Incorrect (wrong-quadrant) responses are recorded as two's complement, and lapses as 250 (i.e., $2.5 \mathrm{sec}$ ). This task is sensitive to sleep-loss effect (e.g., Glenville, Broughton, Wing, \& Wilkinson, 1978).

The listing-scoring program calculates the means and standard deviations for all correct responses, the $10 \%$ fastest and $10 \%$ slowest correct responses, the incorrect responses, and counts of number correct and incorrect responses, lapses, and percent-correct responses.

\section{Logical Reasoning Task}

This task was devised by Baddeley (1968) to measure complex information processing. It consists of random presentation on a video screen of 1 of 16 sentences followed by a pair of letters (AB or BA). The subject is told to type a " 1 " if the sentence is a true description of the letter pair (i.e., "A follows B" BA) and a "2" if the sentence incorrectly describes the letter pair (i.e., "A is preceded by $B$ " $A B$ ). After the subject types a 1 or a 2 , that response is displayed next to the sentenceletter pair. If the subject changes his or her mind about this response, the subject can delete the response and retype a 1 or a 2 . If the subject thinks that the response is correct, he or she enters this response by depressing the ENTER or RETURN key, at which time the next sentence-letter pair appears. At the end of this 3-min task, the number codes for the sentence-letter pairs given and the subject's response to each sentence-letter pair attempted are stored on the output floppy disk.

The listing-scoring program counts the number of sentence-letter pairs attempted and the number correct, and calculates the percent correct. Another program used for a period of familiarizing and training the subjects prints all the questions, the subject's answers, and the correct answers.

\section{Measurements of Mood, Fatigue, and Physiological Status}

This program is a series of mood and physical-symptom questionnaires with instructions followed by prompts asking the subjects to enter readings of oral temperature, blood pressure, and grip strength. The program stores the responses on floppy diskettes. The first questionnaire presented is like the Profile of Mood States (POMS; McNair, Lorr, \& Droppleman, 1971). The 65 items in the questionnaire appear one at a time on the video screen, below the instructions on how to use the 4 point response scale, entering or deleting their response to each item. The subject presses a numeric key corresponding to how each item described his or her mood and then presses the ENTER or RETURN key on the terminal to record the response. A subject can change his or her response before it is entered by pressing the DELETE 
key and entering a new response. Only after pressing a response value within the correct range and the RETURN or ENTER key is the response stored and the next item presented.

After the POMS, the School of Aerospace Medicine (SAM) Subjective Fatigue Checklist instructions and its 10 items (Naitoh, 1981; Pearson \& Byars, 1956) are presented in a similar manner. The next questionnaire is the 29-item Naval Health Research Center (NHRC) Mood Questionnaire (Moses, Lubin, Naitoh, \& Johnson, 1974), which Opstad et al. (1978) found to be sensitive to sleep loss and fatigue. This is followed by the 30 item Kogi Symptom Checklist (Englund et al., 1983; Kogi, Saito, \& Mitsuhashi, 1970). For all these questionnaires, the instructions on the use and recording of responses remains on the screen, and one item is presented at a time.

Following these questionnaires, the subject is asked to enter oral temperature, systolic and diastolic blood pressure, and grip strength of left and right hands, as measured with a hand dynamometer. The Stanford Sleepiness Scale (SSS; Hoddes, Zarcone, Smythe, Phillips, \& Dement, 1973) is the last request for a response.

The upper and lower ranges for these physiological data are checked when entered; out-of-range values are not stored, but, instead, cause a comment to appear and then a redisplay of the prompt requesting the input of that physiological datum.

When the last subject has entered a valid response to the SSS, all the values to the questionnaires and other variables are stored on diskette with the time of day (in ticks of 100ths of seconds since midnight) at which the last value was entered.

The scoring program computes the scores of six scales in the POMS, the total score for the SAM Subjective Fatigue Checklist, the negative and positive scales on the NHRC Mood Questionnaire, and the total "Yes" answers to symptoms on the KOGI. The oral temperature (in both Fahrenheit and Celsius), the systolic and diastolic blood pressures, the grip strength (in kilograms) of the left and right hands, and the SSS responses are also printed out, along with the team, session, day file name, subject information, and time at which the task ended.

\section{SUMMARY}

All scoring programs analyze every session, with the data from specific blocks of the session files on one disk. There is an option to output all scores to disk to facilitate transferring data to a computer system where the data are analyzed. Other scoring programs produce session means each day for the experimental and control subjects. The scores generated by these programs can also be stored on floppy diskettes, and the contents of these scores can be transferred to IBM or VAX computer systems for further statistical analyses.
These programs have been run on a MINC 11/03 and MINC 11/23 with clock (MNCKW) and A/D converter (MNCAD) modules and with VT105 and VT100 video display terminals. The scoring programs require a printer (LA120). The four-choice and similar moodphysiology surveys have been adapted for the CROMENCO Model 2CS. Converting the six task programs from the MINC 11 system to a PDP-11 would require changing all clock calls and the peripheral addresses and conversion of any $A / D$ signal.

Listings or floppy-diskette copies of the task or scoring programs can be obtained by writing to the senior author at the Naval Health Research Center. Requests for floppy-diskette copies must be accompanied by a blank soft-sectored (SS/DD) 8-in. diskette.

\section{REFERENCES}

Angus, R. G., Innes, L. G., Heselgrave, R. J., \& Pearce, D. G. (1983, April). The effects of sleep loss in sustained mental work: Implications for command control performance. Pro. ceedings of Sustained Intensive Error Operation: Physiological Performance Aspects (pp. 11-1-11-21). AGARD \#338. (DTIC, Alexandria, VA)

BADDELEY, A. D. (1968). A 3-minute reasoning test based on grammatical transformation. Psychonomic Science, 10, 341-342.

Companion, M. A., \& Corso, G. M. (1982). Task taxonomies: A general review and evaluation. International Journal of ManMachine Studies, 17, 459-472.

Donder, F. C. (1868). Die Schnelligkeit Psychischer Prozesse. Archiv fur Anatomie ünd Physiologie und wissenschaftliche Medizen, 657-681.

EcoSystems, INC. (1977). Manual for performance measurement system PMS MARK 1-77. Philadelphia: Author.

Englund, C. E., Naitoh, P., Ryman, D. H., \& Hodgdon, J. A. (1983). Moderate physical work effects on performance and mood during sustained operations (Tech. Rep. No. 83-6). San Diego: Naval Health Research Center.

Foree, D. D., Eckerman, D. A., Elliot, S. L. (1984). M.T.S.: An adaptable microcomputer-based testing system. Behavior Research Methods, Instruments, \& Computers, 16, 223-229.

Friedmann, J., Globus, G. G., Huntley, A., Mullaney, D., Naitoh, P., \& Johnson, L. C. (1977). Performance and mood during and after gradual sleep reduction. Psychophysiology, 14, 245-250.

Glenville, M., Broughton, R., Wina, A. B., \& Wilkinson, R. T. (1978). Effects of sleep deprivation on short duration performance measures compared to the Wilkinson auditory vigilance test. Sleep, 1, 169-176.

Grice, G. R., Nullmayor, R., \& Spiker, V. (1982). Human reaction time: Toward a general theory. Journal of Experimental Psychology, 111, 135-153.

Hartman, B. O., Benel, R. A., \& Storm, W. F. (1980). A review of USAFSAM studies employing multiple-task performance devices (Tech. Rep. No. SAM-TR 80-16). San Antonio: U.S. Air Force School of Aerospace Medicine.

Herscovitch, J., \& Broughton, R. (1981). Performance deficits following short-term partial sleep deprivation and subsequent recovery oversleeping. Canadian Journal of Psychology, 35, 309-322.

Heselgrave, R. J., \& Angus, R. G. (1983, May). Sleep loss and sustained performance. Paper presented at NATO Defense Research Group seminar, Toronto.

Hoddes, E., Zarcone, V., Smythe, H., Phillips, R., \& Dement, W. C. (1973). Quantification of sleepiness: A new ap- 
proach. Psychophysiology, 10, 431-436.

HoRD, D. J. (1982). An EEG predictor of performance decrement in a vigilance task (Tech. Rep. No. 82-2). Naval Health Research Center.

Kennedy, R. S., Bittiner, A. C., Carter, R. C., Krause, M., Hareeson, M. M., McCafferty, D. B., Pepper, R. L., \& WIKER, S. F. (1980). Performance evaluation tests for environmental research (PETER): Collected papers (Tech Rep. No. NBDL-80R008). New Orleans: Naval Biodynamic Laboratory.

Kogi, K., Saito, Y., \& Mitsuhashi, T. (1970). Validity of three components of subjective fatigue feelings. Journal of Science of Labour, 46, 251-270.

Lisper, H., \& KJELlBerg, A. (1972). Effects of a 24-hour sleep deprivation on rate of decrement in a 10-minute auditory reaction time task. Journal of Experimental Psychology, 96, 287-290.

McKenzie, R. E., White, D. D., \& Hartman, B. O. (1969). NEPTUNE: A multi-element task system for evaluating human performance (Tech. Rep. No. SAM-TR 69-25). San Antonio: U.S. Air Force School of Aerospace Medicine.

McNair, D. M., Lorr, M., \& Droppleman, L. F. (1971). Profile of Mood Scale. San Diego, CA: Educational and Industrial Testing Service.

Moran, L. J., \& Mefferd, R. B., JR. (1959). Repetitive psychometric measures. Psychological Reports, 5, 269-275.

Morgan, B. B., Jr., Brown, B. R., \& Alluisi, E. A. (1974). Effects on sustained performance of 48 hour of continuous work and sleep loss. Human Factors, 16, 406-414.

Moses, J. M., Lubin, A., Naitoh, P., \& Johnson, L. C. (1974). Subjective evaluation of the effects of sleep loss: The NHRC mood scales (Tech Rep. No. 74-25). San Diego: Naval Health Research Center.

Mullaney, D. J., Kripke, D. F., Fleck, P. A., \& Johnson, L. C. (1983). Sleep loss and nap effects on sustained continuous performance. Psychophysiology, 20, 643-651.

Natтон, P. (1981). Circadian cycle and restorative power of naps.
In L. C. Johnson, D. I. Tepas, W. P. Colquhoun, \& M. J. Colligan (Eds.), Biological rhythms, sleep and shiftwork. Jamaica, NY: Spectrum Publications.

Naitoh, P., Englund, C. E., \& Ryman, D. H. (1982). Restorative power of naps in designing continuous work schedules (Tech. Rep. No. 82-25). San Diego: Naval Health Research Center.

Olson, G. M., Moeller, G., \& Laxar, K. (1973). RTLAB: A reaction-time laboratory for the Data General NOVA computer (Tech. Rep. No. 748). Groton, CT: Naval Submarine Medical Research Laboratory.

Opstad, P. K., Ekanger, R., Nummestad, M., \& RaAbe, N. (1978). Performance, mood, and clinical symptoms in men exposed to prolonged, severe physical work and sleep deprivation. Aviation, Space and Environmental Medicine, 49, 1065-1073.

Pearson, R. G., \& Byars, G. E. (1956). The development and validation of checklist for measuring subjective fatigue (Tech. Rep. No. 56-115). San Antonio: U.S. Air Force School of Aerospace Medicine.

Reilly, R. E., \& Cameron, B. J. (1968). An integrated measurement system for the study of human performance in the underwater environment (ONR Contract No. N00014-67-C-0410, Work Unit No. NR 196-074). Falls Church, VA: Biotechnology.

Thorne, D., Genser, S., Sing, H., \& Hegge, F. (1983, XXXX). Plumbing human performance limits during 72 hours of high task load. Paper presented at NATO Defense Research Group seminar, Toronto.

Wilkinson, R. T. (1964). Effects of up to 60 hours' sleep deprivation on different types of work. Ergonomics, 7, 175-186.

Wilkinson, R. T., \& Houghton, D. (1975). Portable four-choice reaction time test with magnetic tape memory. Behavior $\boldsymbol{R e}$ search Methods \& Instrumentation, 7, 441-446.

Williams, H. L., Lubin, A., \& Goodnow, J. J. (1959). Impaired performance with acute sleep loss. Psychological Monographs, 73(14, Whole No. 484). 